\title{
Exames radiográficos simples e tomográficos do segmento lombossacro da coluna vertebral em cães da raça Pastor Alemão: estudo comparativo
}

Thelma Regina Cintra da SILVA ${ }^{1}$

Carolina de Oliveira GHIRELLI ${ }^{1}$

Ayne Murata HAYASHI ${ }^{1}$

Alex Jader SANT'ANA ${ }^{2}$

Julia Maria MATERA ${ }^{1}$

Ana Carolina Brandão de

Campos FONSECA PINTO ${ }^{1}$

\section{Correspondência para:}

Av. Prof. Orlando Marques de Paiva 87, São Paulo, SP 05508-900, Brasil, thelmacintra@yahoo.com.br

Recebido para publicação: 14/08/2008 Aprovado para publicação: 29/06/2009

\author{
1 - Departamento de Cirurgia da Faculdade de Medicina Veterinária e Zootecnia \\ da Universidade de São Paulo, São Paulo-SP \\ 2 - Departamento de Cirurgia da Faculdade de Medicina da Universidade de São \\ Paulo, São Paulo-SP
}

\section{Resumo}

O termo síndrome da cauda equina (SCE) define as manifestações clínicas oriundas da disfunção sensorial e/ou motora causada pela lesão das raízes nervosas que formam a porção terminal da medula espinhal. A estenose lombossacra é a causa mais comum, correlacionando-se às alterações das partes moles e/ou tecidos ósseos neste segmento. Este estudo teve por objetivo realizar uma análise crítica da contribuição dos métodos de imagem, quais sejam exames: radiográfico simples e tomográfico, para avaliação do segmento lombossacro em 30 cães da raça Pastor Alemão. Sendo treze animais pertencentes ao grupo (A) sem manifestações clínicas e alterações radiográficas no segmento lombosacro; doze animais pertencentes ao grupo (B) sem manifestações clínicas com alterações radiográficas no segmento lombossacro e cinco animais pertencentes ao grupo $(\mathrm{C})$ com manifestações clínicas e portadores de alterações radiográficas no segmento lombossacro. Todos os exames foram submetidos a um protocolo de avaliação. $\mathrm{O}$ exame tomográfico mostrou-se superior na avaliação do canal vertebral, foramens intervertebrais e processos articulares, os quais puderam ser avaliados com maior riqueza de detalhes. Concluiu-se com esta pesquisa que as duas modalidades de imagem se complementam, constituindo ferramentas importantes na avaliação clínico-cirúrgica do segmento lombossacro, auxiliando no diagnóstico, estabelecimento do prognóstico e da terapêutica a ser adotada.

\section{Introdução}

A expressão cauda equina é usada para descrever as raízes e nervos espinhais lombares, sacrais e caudais que transitam a partir da porção terminal da medula espinhal. ${ }^{1,2,3,4,5,6} \mathrm{O}$ nome síndrome da cauda equina (SCE) define as manifestações clínicas da disfunção sensorial e/ou motora causada pela lesão das raízes nervosas que formam a porção terminal da medula espinhal. ${ }^{3}$

Os nervos periféricos que formam a cauda equina e têm importância clínica são os nervos isquiáticos, originados nos segmentos medulares L7-S1, que inervam os músculos extensores das articulações coxofemorais, músculos flexores das articulações fêmorotibiais e os flexores e extensores digitais; os nervos pudendos, originados pelos segmentos medulares S2 e S3, que inervam o esfíncter uretral e anal, músculos da vulva e pênis, prepúcio e escroto; os nervos pélvicos que se originam das raízes nervosas de S2 e S3 e inervam as vísceras pélvicas e órgãos genitais; e os nervos caudais, constituídos por segmentos medulares de Co1 a Co5, e que determinam funções sensoriais e motoras da cauda.,

A estenose lombossacra degenerativa é a causa mais comum de SCE nos cães de raças de grande porte, em particular os Pastores Alemães. ${ }^{7}$ Ela pode resultar em 
manifestações clínicas como: dor na região lombossacra, incoordenação dos membros pélvicos ou claudicação e incontinência urinária e/ou fecal. As manifestações clínicas frequentemente têm um aparecimento súbito progredindo gradualmente ao longo de meses; tornando-se um quadro clínico incerto, especialmente quando acomete cães portadores de displasia coxofemoral. ${ }^{9}$

A definição e a classificação da estenose do canal vertebral são controversas e até certo ponto arbitrárias. Foi definida, em 1976, por um grupo de ortopedistas como sendo qualquer tipo de estreitamento do canal vertebral, canal radicular ou forâmen intervertebral ${ }^{10}$, sendo classificada por Tarvin e Prata ${ }^{11}$ como adquirida (degenerativa) ou congênita (desenvolvimento). O estreitamento pode ser local, segmentar ou generalizado, sendo determinado por estruturas ósseas, partes moles ou ambos ${ }^{10}$. Segundo Rossi et al. ${ }^{12}$ a compressão neural é causada por uma combinação de degeneração e abaulamento discal (Hansen tipo II) no segmento lombossacro e por alterações degenerativas hipertróficas dos processos articulares, ligamentos e corpos vertebrais.

Os pacientes com SCE frequentemente apresentam os reflexos dos membros pélvicos normais, embora o reflexo patelar possa estar exacerbado. Isto devido à flacidez da musculatura caudal da coxa a qual é inervada pelo ciático e no aumento da ação dos grupos musculares que constituem o quadríceps. ${ }^{6,13}$

Outra afecção acomete esse segmento da coluna vertebral, a listese. O termo espondilolistese é atribuído a espôndilo, o qual significa vértebra e listesis, escorregamento. ${ }^{10}$ Segundo Thrall ${ }^{14}$, a instabilidade lombossacra é a afecção de maior dificuldade para ser diagnosticada. Ela ocorre quando há um deslocamento ventral do sacro (S1) em relação à epífise caudal de L7. ${ }^{12,13}$

Os cães de grande porte como Pastor Alemão, Rottweiler e Labrador Retriever são mais comumente afetados por alterações envolvendo o segmento lombossacro.
Diferenças raciais específicas na conformação anatômica da região lombossacra e o tipo de movimento na junção discovertebral representam um importante papel no acometimento desta região. ${ }^{12}$ Os cães de meia-idade a idosos, de raças de grande porte (especialmente os Pastores Alemães) são, frequentemente, mais acometidos pela SCE; sendo os machos são mais susceptíveis do que as fêmeas, pelo fato de crescerem mais rápido, possuírem peso e comprimento do corpo maior e serem mais exigidos. ${ }^{15,16,17}$

As parestesias existentes, na estenose do canal vertebral lombossacro, podem decorrer da irritação de fibras sensoriais da cauda equina, provenientes de dermátomos inervados pelos nervos pudendo, ciático e caudais. ${ }^{2,18,19}$ Outros distúrbios que desencadeiam automutilação da cauda, genitália e membros pélvicos são: dermatopatias, epilepsias, neuroma de caudectomia, orquites, ganglioradiculoneuropatias e neuropatias sensoriais, assim como a síndrome de hiperestesia idiopática. ${ }^{20,21,22} \mathrm{Em}$ geral, cães com lesões decorrentes da parestesia, gerada pela compressão da cauda equina, são primeiramente tratados contra problemas dermatológicos mal definidos. ${ }^{23}$ Esquecendo-se de que a irritação das raízes dos nervos ciáticos, pudendos e caudais podem também levar à automutilação dos membros pélvicos; genitália, ânus e períneo, ou cauda. ${ }^{2,18,19}$

Deve-se primeiro realizar um exame ortopédico dos membros pélvicos, seguido de um exame neurológico meticuloso; incluindo uma avaliação da propriocepção consciente, da função motora, dos reflexos, do estado sensorial, do tono anal e do estado da continência (a partir da história médica do paciente). ${ }^{5}$ Mais relevante, o clínico deve palpar a região lombossacra para definir a presença ou não de dor. A dor lombar tem sido o achado mais consistente em todos os casos descritos. ${ }^{5}$

Vários meios de diagnóstico vêm sendo utilizados para avaliar o segmento lombossacro da coluna vertebral. Aqui se incluem: as radiografias convencionais e sob 
estresse (flexão e extensão dos membros pélvicos), mielografia, epidurografia, discografia, venografia, eletromiografia, tomografia computadorizada (TC) e ressonância magnética. ${ }^{10,13,24,25}$ Dentre os exames contrastados, a mielografia e a epidurografia são as mais utilizadas, porém com baixa sensibilidade. ${ }^{13}$ Sabe-se, entretanto, que apenas uma modalidade de imagem pode não conseguir obter o diagnóstico das diferentes formas de compressão da cauda eqüina. ${ }^{26}$

As radiografias convencionais são um método de diagnóstico rápido, simples e que promove uma extensa avaliação do segmento lombossacro. Por outro lado, devido à baixa capacidade na diferenciação de tecidos moles pode levar a erros de interpretação, além da asa do ílio e o sacro obscurecerem o forâmen intervertebral de L7-S1, limitando desta maneira a sua indicação nos pacientes com suspeita de SCE. ${ }^{6,13,27}$ As alterações no segmento lombossacro que podem ser determinadas pelas radiografias convencionais são: espondilose deformante ventral, dorsal e lateral, esclerose das faces articulares de L7-S1, diminuição do espaço intervertebral entre L7-S1, osteoartrose nos processos articulares de $\mathrm{L} 7$ e S1, listese ventral de S1 em relação à L7, discoespondilite, estenose lombossacra, vértebra de transição, neoplasia óssea, osteocondrose sacral e trauma. . $13,19,27,28,29$ Sendo que a espondilose, listese, esclerose das faces articulares de L7 e/ou S1 e diminuição do espaço intervertebral L7-S1 podem ou não estar associadas com SCE, além de estarem presentes em muitos cães idosos de raças de grande porte assintomáticos. ${ }^{27,30}$

A tomografia da região lombossacra sem contraste no canal vertebral é preferencial em função desta substância poder causar artefatos, os quais dificultam a interpretação. ${ }^{13}$ Alguns achados tomográficos de cães portadores de afecção na junção lombossacra: diminuição da gordura epidural, obliteração do forâmen intervertebral, protrusão discal, espondiloses, deslocamento do saco dural, estreitamento do forâmen intervertebral e canal vertebral (estenose), osteófitos, subluxação ou espessamento dos processos articulares. . $^{13,31,32}$ Entretanto, algumas alterações tomográficas, tais como a estenose do canal vertebral e a diminuição da gordura epidural, na junção lombossacra, podem ser insignificantes clinicamente, especialmente em cães idosos. ${ }^{31}$

Quando sinais clínicos consistentes de SCE estejam presentes, deve-se suspeitar, à TC, de uma compressão no local onde exista uma hiperatenuação dos tecidos moles e ausência de gordura epidural. ${ }^{13}$

O abaulamento do disco intervertebral pode ser um achado tomográfico em cães sadios, ou seja, o disco intervertebral pode apresentar um aspecto achatado ou ligeiramente convexo na junção lombossacra em pacientes normais; embora esta condição predisponha futuramente ao aparecimento de manifestações clínicas. ${ }^{32} \mathrm{~A}$ degeneração dos processos articulares dos corpos vertebrais aparece na TC como uma diminuição de espaço entre esses processos acompanhada de osteófitos peri-articulares, esclerose do osso subcondral, cistos subcondrais e/ou hipertrofia desses processos. O deslocamento de tecidos nervosos mostra-se por um desvio, deformidade ou reentrância dos trajetos nervosos e/ou saco dural. ${ }^{31}$

Acredita-se que a degeneração do disco intervertebral entre L7-S1, seguida da formação de osteófitos, sejam os agentes causadores desta síndrome. ${ }^{8,15}$ Associado à perda da função do disco intervertebral ocorre um estreitamento do forâmen intervertebral e subluxação das facetas dos processos articulares de L7 e S1. Tal fato pode levar ao espessamento e invaginação do ligamento amarelo. A associação de tais processos causaria então a compressão da cauda equina. Além disso, a tração ou deslocamento da cauda equina podem causar lesões como neuropraxia e até transecção completa de nervos; sendo que a avulsão de raízes nervosas provocam déficits neurológicos permanentes. O edema e hemorragia também podem causar compressão, porém o prognóstico deve ser 
sempre baseado no exame neurológico e não na imagem radiográfica. ${ }^{8}$

O presente trabalho teve como objetivo realizar o exame radiográfico simples, com radiografias convencionais e sob estresse (ventroflexão e dorsoextensão) e tomográfico da região lombossacra de cães da raça Pastor Alemão, portadores ou não de sinais clínicos. Procurou-se, desta maneira, determinar a contribuição dos exames radiográficos e tomográficos para o estabelecimento do diagnóstico da síndrome da cauda equina.

\section{Material e Método}

O estudo radiográfico e tomográfico simples da região lombossacra foi realizado em 30 cães da raça Pastor Alemão no serviço de Diagnóstico por Imagem do Hospital Veterinário da Faculdade de Medicina Veterinária e Zootecnia da Universidade de São Paulo. Este projeto de pesquisa foi julgado e aprovado pela Comissão de Bioética da Faculdade de Medicina Veterinária e Zootecnia da Universidade de São Paulo. Esses cães foram divididos em três grupos. Os critérios de inclusão em cada grupo foram manifestações clínicas, exame neurológico e aspectos radiográficos da junção lombossacra: Grupo A: 13 cães sem sinais clínicos e alterações radiográficas na região lombossacra e com exame neurológico normal, Grupo B: 12 cães sem sinais clínicos, exame neurológico normal, porém com alterações radiográficas na região lombossacra, Grupo C: cinco cães com sinais clínicos, exame neurológico alterado e portadores de alterações radiográficas na região lombossacra.

Os cães foram submetidos aos exames de imagem após a sedação, via intramuscular, com acepromazina na dose de $0,05 \mathrm{mg} / \mathrm{kg}$ e butorfanol na dose de 0,2 $\mathrm{mg} / \mathrm{kg}$; e monitorização pela auscultação cardíaca e contagem de frequência respiratória.

Os exames radiográficos foram realizados em aparelhos de radiodiagnóstico, marca RAY-TEC, de $500 \mathrm{~mA}$ e $125 \mathrm{kV}$, modelo RT 500/125 e o outro da marca Tecno Designer, alta frequência, de $500 \mathrm{~mA}$ e $120 \mathrm{Kv}$, modelo TD $500 \mathrm{HF}$, ambos com mesa radiológica portando grade antidifusora. Foram utilizados os filmes radiográficos, TMS-1 e MXG/PLUS, de tamanhos $24 \mathrm{X} 30 \mathrm{~cm}, 30 \mathrm{X} 40 \mathrm{~cm}$ e $35 \mathrm{X} 43 \mathrm{~cm}$, colocados em chassi metálico portando telas intensificadoras CRONEX HI plus, selecionados de acordo com as dimensões da região a ser radiografada e porte do animal. Os filmes foram revelados e fixados em Processadora Automática RPX-OMAT ou MX-2, após identificação luminosa apropriada.

As imagens radiográficas foram obtidas em duas projeções: láterolateral (decúbito lateral direito) e ventrodorsal. No decúbito lateral foram realizadas três radiografias, sendo uma com os membros pélvicos numa posição neutra; outra com os membros pélvicos em ventroflexão e outra em dorsoextensão (Figura 1). No decúbito dorsal foi realizada uma radiografia com os membros pélvicos estendidos, tracionados e rotacionados medialmente, com o cuidado de manter a simetria das articulações sacroilíacas, coxofemorais e fêmorotibiopatelares.

A análise radiográfica seguiu o protocolo de avaliação que levava em consideração os seguintes itens: presença de vértebra de transição (V'T) com fusão ou não do processo transverso com o sacro e ou ílio, espondilose ventral, dorsal e lateral, diminuição do espaço intervertebral (DEIV), calcificação do disco intervertebral (CDIV) e do ligamento longitudinal dorsal ou paquimeninge, opacificação do forâmen intervertebral (OFIV), degeneração das articulações sacroilíacas (DSI), displasia coxofemoral (DCF) e osteoartrose nas articulações coxofemorais.

O exame de tomografia computadorizada do segmento lombossacro da coluna vertebral foi realizado em equipamento CT-MAX 640 de terceira geração. As imagens foram fotografadas em câmera multiformato MFC640 em filmes da marca Kodak Ektanscan M tamanho $35 \mathrm{x} 43 \mathrm{~cm}$, os quais foram revelados e fixados 


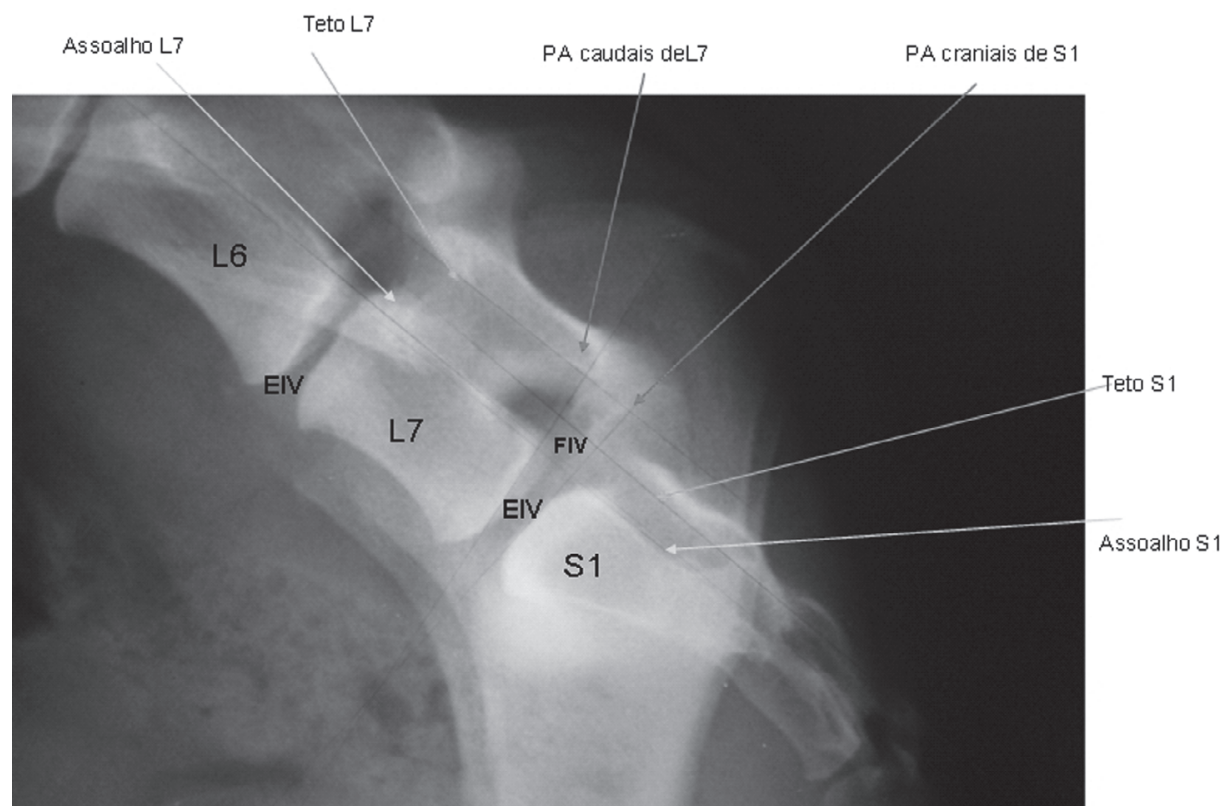

Figura 1 - Imagem radiográfica digitalizada da junção lombossacra ilustrando pontos anatômicos, onde PA processos articulares, EIV - espaço intervertebral, FIV - forâmen intervertebral - São Paulo - 2008

em Processadora Automática RPX-OMAT ou MX-2.

Os cães foram posicionados em decúbito dorsal (posição supinada) com os membros pélvicos primeiramente na entrada do aparelho (gantry), os quais foram ligeiramente flexionados na tentativa de minimizar qualquer desvio lordótico da junção lombossacra. Foi realizada a radiografia digital, permitindo assim a exata localização dos cortes obtidos. Procederamse cortes perpendiculares ao canal vertebral e paralelos à epífise cranial de L7 e S1 e espaço intervertebral (EIV) de L7-S1, com $5 \mathrm{~mm}$ de espessura e $5 \mathrm{~mm}$ de incremento. Os cortes iniciaram-se na epífise caudal de L7 se estendendo até a epífise cranial de S1. No corte correspondente ao EIV de L7-S1 também foi realizado corte de $2 \mathrm{~mm}$ de espessura com angulação, se necessária, do gantry para obtenção de corte tangencial ao espaço intervertebral de L7-S1, além de técnica de reconstrução em janela óssea para obtenção de imagem mais detalhada do espaço em questão.

A análise tomográfica seguiu o protocolo de avaliação que levava em consideração os seguintes itens: simetria das articulações sacroilíacas, protrusão central ou lateral do disco intervertebral (PDIV), morfologia dos processos articulares (PA) caudais de L7 e craniais de S1, obliteração/ opacificação dos foramens intervertebrais (OFIV), diminuição da gordura epidural (DGEP), espondilose ventral (EV), lateral (EL) e dorsal (ED) e deslocamento do saco dural (DSD) (Figura 2).

\section{Resultados}

Na tabela 1 observa-se a distribuição dos cães nos três diferentes grupos segundo sexo, idade e peso. Notou-se que a maioria, segundo o sexo, eram fêmeas. Pode-se ainda observar que houve uma pequena variação de peso e idade dos cães nos três diferentes grupos, sendo que o grupo $\mathrm{C}$ caracterizouse por ser o de menor peso e maior idade.

É importante ressaltar que o critério de inclusão dos cães no grupo A foi a ausência de alterações radiográficas na região lombossacra.

\section{Discussão}

Os cães da raça Pastor Alemão 


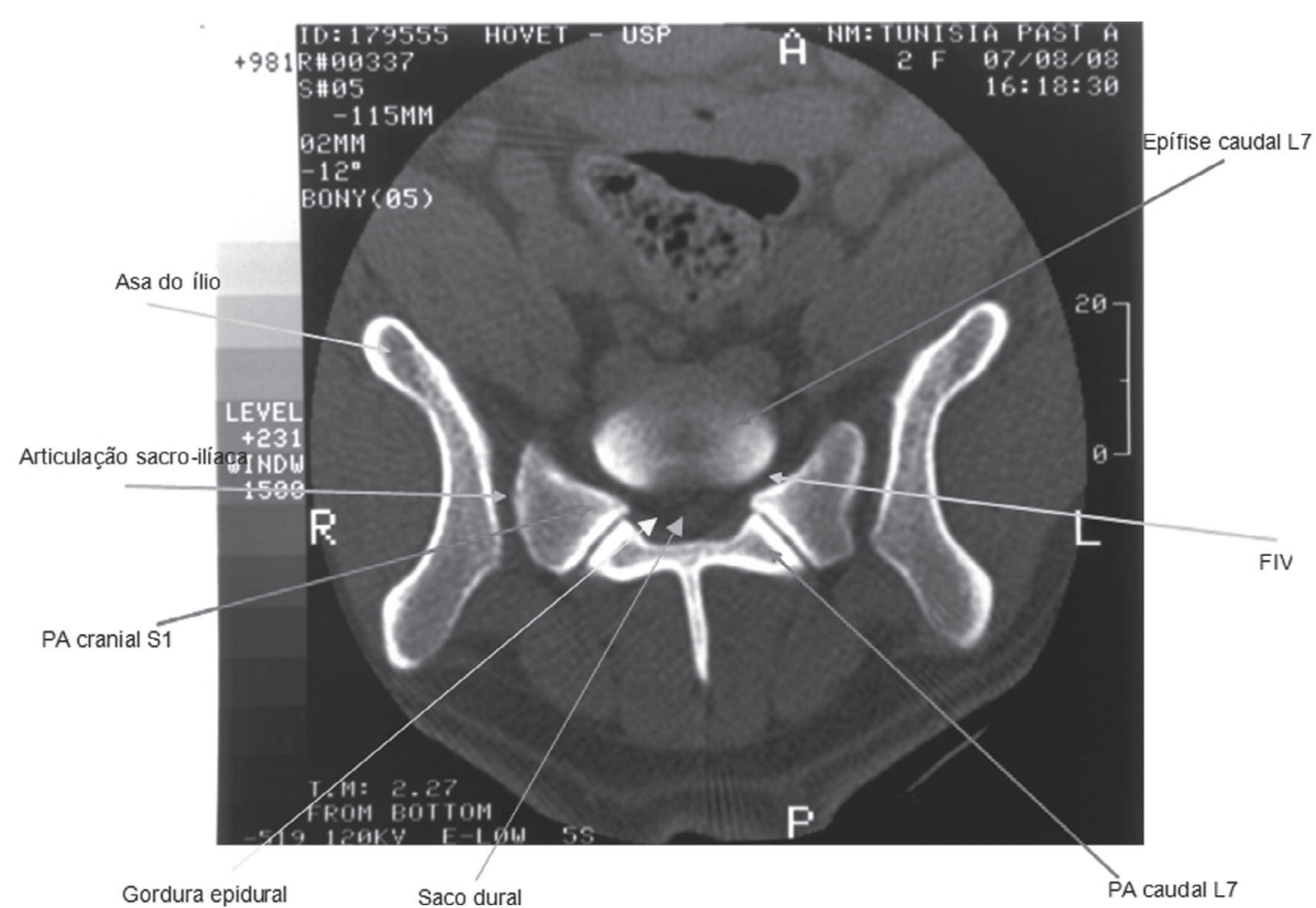

Figura 2 - Imagem tomográfica digitalizada, com corte de 02mm de espessura, no EIV entre L7-S1 ilustrando pontos anatômicos, onde PA- processos articulares e FIV - forâmen intervertebral. Notar os aspectos tomográficos normais das articulações sacro-ilíacas, processos articulares, gordura epidural hipoatenuante, saco dural e altura dos foramens intervertebrais - FMVZ-USP- São Paulo - 2008

possuem a conformação anatômica da região lombossacra diferenciada, além da alta incidência de degeneração do disco intervertebral neste segmento quando comparados com outras raças. ${ }^{12,32,33} \mathrm{Em}$ concordância aos autores citados previamente, decidiu-se estabelecer esse padrão racial para a presente pesquisa.

Embora o exame radiográfico possa ser útil, afecções lombossacrais podem ocorrer sem alterações radiográficas, e modificações ósseas podem estar presentes em cães sem evidências clínicas de doença ${ }^{32}$ (Figura 3), como se observou na avaliação das imagens radiográficas dos animais do grupo B (assintomáticos): 58,33\% com DEIV, $75 \%$ com OFIV e $66,66 \%$ com espondiloses entre L7-S1 (Quadro 1).

Lesões na região lombossacra determinam um quadro clínico incerto quando acometem animais portadores de displasia coxofemoral (DCF), sobretudo o Pastor Alemão por ser uma raça com alta incidência tanto de estenose degenerativa

Tabela 1 - Distribuição dos trinta cães nos três grupos em estudo segundo sexo, idade e peso - São Paulo - 2008

\begin{tabular}{ccccc}
\hline Grupos & No Cães $^{\text {Sexo }}$ & Idade (anos) & Peso (kg) \\
\hline $\mathrm{A}$ & 13 & $6 \mathrm{M} / 7 \mathrm{~F}$ & $2,3 \pm 1,7$ & $32,07 \pm 5,74$ \\
$\mathrm{~B}$ & 12 & $3 \mathrm{M} / 9 \mathrm{~F}$ & $3,6 \pm 2,1$ & $31,43 \pm 5,52$ \\
$\mathrm{C}$ & 5 & $1 \mathrm{M} / 4 \mathrm{~F}$ & $5,2 \pm 2,7$ & $30,28 \pm 3,68$
\end{tabular}

No: número; M: macho; F: fêmea; 

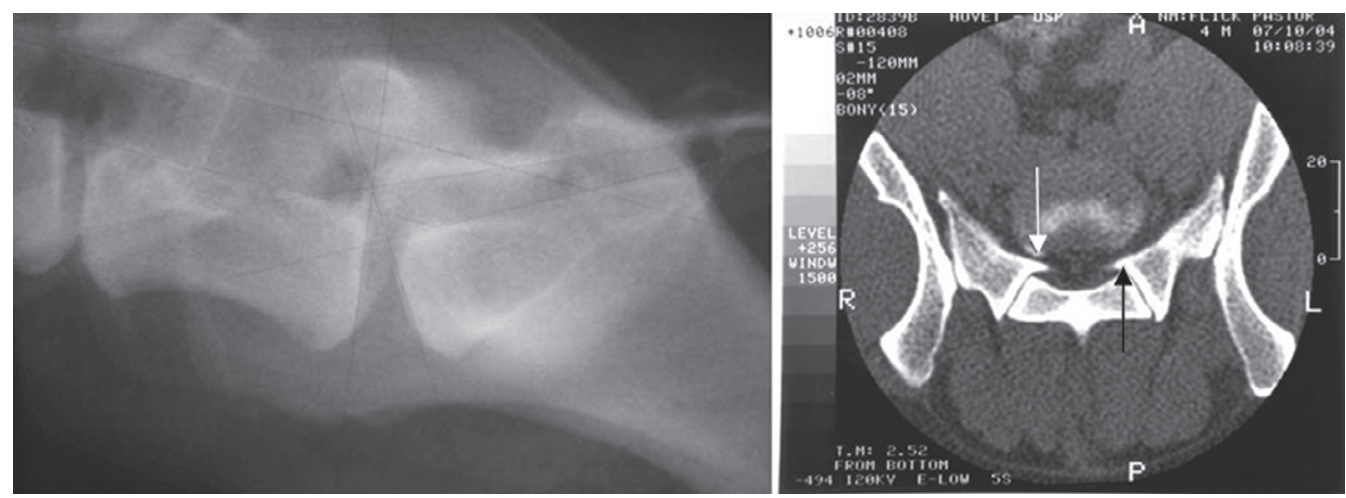

Figura 3 - Imagem radiográfica da região lombossacra na posição sob dorso-extensão dos membros pélvicos e tomográfica digitalizadas com corte transversal de $02 \mathrm{~mm}$ de espessura, no espaço intervertebral entre L7-S1, de um cão do grupo A. Visibilizou-se à TC protrusão de disco intervertebral lateral à direita leve com obliteração do forâmen intervertebral direito (seta branca) e processos articulares craniais de S1 em maior evidência (seta preta). FMVZ-USP - São Paulo - 2008

Quadro 1 - Percentual de achados radiográficos na região lombossacra nos cães dos três grupos em estudo (VT: vértebra de transição; DEIV: diminuiçãa de espaço intervertebral; CDIV: calcificação de disco intervertebral; OFIV: opacificação de forâmen intervertebral; DCF: displasia coxofemoral) - São Paulo - 2008

\begin{tabular}{|l|c|c|c|}
\hline Achados radiográficos & Grupo A & Grupo B & Grupo C \\
\hline VT & 0 & $33,3 \%$ & 0 \\
\hline Osteófito/Espondilose anquilosante & 0 & $66,66 \%$ & $60 \%$ \\
\hline DEIV & 0 & $58,33 \%$ & $40 \%$ \\
\hline $\begin{array}{l}\text { CDIV e Ligamento longitudinal dorsal/ } \\
\text { paquimeninge }\end{array}$ & 0 & 0 & 0 \\
\hline OFIV & 0 & $75 \%$ & $100 \%$ \\
\hline Degeneração das articulações sacro-iliacas & $7,69 \%$ & $50 \%$ & $20 \%$ \\
\hline DCF & $46,15 \%$ & $41,66 \%$ & $60 \%$ \\
\hline Osteoartrose das articulações coxofemorais & $23,07 \%$ & $33,33 \%$ & $40 \%$ \\
\hline
\end{tabular}

lombossacra como de DCF e mielopatias degenerativas. Desta maneira, estas afecções devem ser avaliadas com cuidado, baseado na análise conjunta do exame ortopédico, neurológico e radiográfico.?

As radiografias convencionais e sob estresse ajudam a avaliar a extensão e a característica do movimento da região lombossacra. A exata função, desta modalidade de imagem, para diagnosticar compressões na cauda equina está ainda incerta. ${ }^{13}$ Compartilha-se com a idéia de que na ventroflexão o canal vertebral fica alargado e na dorso-extensão ocorre um estreitamento no seu diâmetro, visto que os processos articulares craniais de $\mathrm{S} 1$ insinuamse em direção ao canal vertebral associados a um permitido escorregamento ventral de S1 em relação à L7. ${ }^{11,13,19}$

Em concordância com a afirmação de Mattoon e Koblik $^{27}$ as espondiloses podem estar presentes em animais idosos de raças de grande porte, com ou sem sinais clínicos da SCE, sendo vizibilizado ao exame radiográfico em $66,66 \%$ dos animais do grupo B e $60 \%$ no grupo C. Não podendo estas, serem associadas isoladamente, com estenose lombossacra. Já na tomografia computadorizada (TC), 7,69\% dos animais do grupo A apresentaram EV, 15,38\% EL e 23,07\% ED. No grupo B 33,33\% EV, $41,66 \%$ EL e $25 \%$ ED. No grupo C 60\% EV, $80 \%$ EL e $20 \%$ ED, podendo o mesmo animal possuir espondiloses ventrais, laterais 
e/ou dorsais (Quadro 2). Concorda-se com Ramirez e Thrall ${ }^{13}$, Jones e Inzana ${ }^{31} \mathrm{e}$ Axlund e Hudson ${ }^{32}$ os quais colocam que a TC possui maior sensibilidade na visibilização de lesões degenerativas em tecidos ósseos (Figura 4).

Para a caracterização da vértebra de transição na região lombossacra, ou seja, classificá-la como lombarização ou sacralização é necessária a realização de radiografias exploratórias da coluna vertebral, incluindo a transição cérvicotorácica e principalmente a tóracolombar, como foi preconizado neste estudo (Figura 5). Assim, permite-se realizar a contagem precisa dos corpos vertebrais de cada segmento da coluna vertebral. ${ }^{34}$ No grupo B, dos doze animais, quatro fêmeas
(33,33\%) apresentaram vértebra de transição na coluna vertebral. Sendo duas na região lombossacra com protrusão leve de DIV entre L7-S1. Uma com vértebra de transição na região tóracolombar com protrusão leve de DIV entre L7-S1. E uma com VT na região tóracolombar e lombossacra. Concordou-se, então, de que a vértebra de transição pode promover um cisalhamento e possíveis danos ao disco intervertebral, e sendo mais frequente nas fêmeas, ou seja, estas possuem maior susceptibilidade a desenvolver SCE. ${ }^{17,34}$ É importante lembrar que, não é o sexo que predispõe à síndrome da cauda equina, mas sim a presença de VT. Isso se deve ao fato da VT acelerar a degeneração discal ou o próprio disco

Quadro 2 - Percentual de achados tomográficos na região lombossacra nos cães dos três grupos em estudo (PDIV: protrusão de disco intervertebral; PA: processos articulares; OFIV: obliteração de forâmen intervertebral; DGEP: diminuição de gordura epidural; EV: espondilose ventral; ĚL: espondilose lateral; ED: espondilose dorsal) - São Paulo - 2008

\begin{tabular}{|l|c|c|c|}
\hline Achados tomográficos & Grupo A & Grupo B & Grupo C \\
\hline Assimetria das articulações sacro-iliacas & $69.23 \%$ & $66,66 \%$ & $100 \%$ \\
\hline PDIV & $61,23 \%$ & $66,66 \%$ & $60 \%$ \\
\hline PA L7-S1 & $23,07 \%$ & $66,66 \%$ & $80 \%$ \\
\hline OFIV & $46,15 \%$ & $41,66 \%$ & $80 \%$ \\
\hline DGEP & $27,07 \%$ & $50 \%$ & $60 \%$ \\
\hline EV & $7,69 \%$ & $33,33 \%$ & $60 \%$ \\
\hline EL & $15,38 \%$ & $41,66 \%$ & $80 \%$ \\
\hline ED & $23,07 \%$ & $25 \%$ & $20 \%$ \\
\hline Deslocamento saco dural & $7,69 \%$ & 0 & $20 \%$ \\
\hline
\end{tabular}
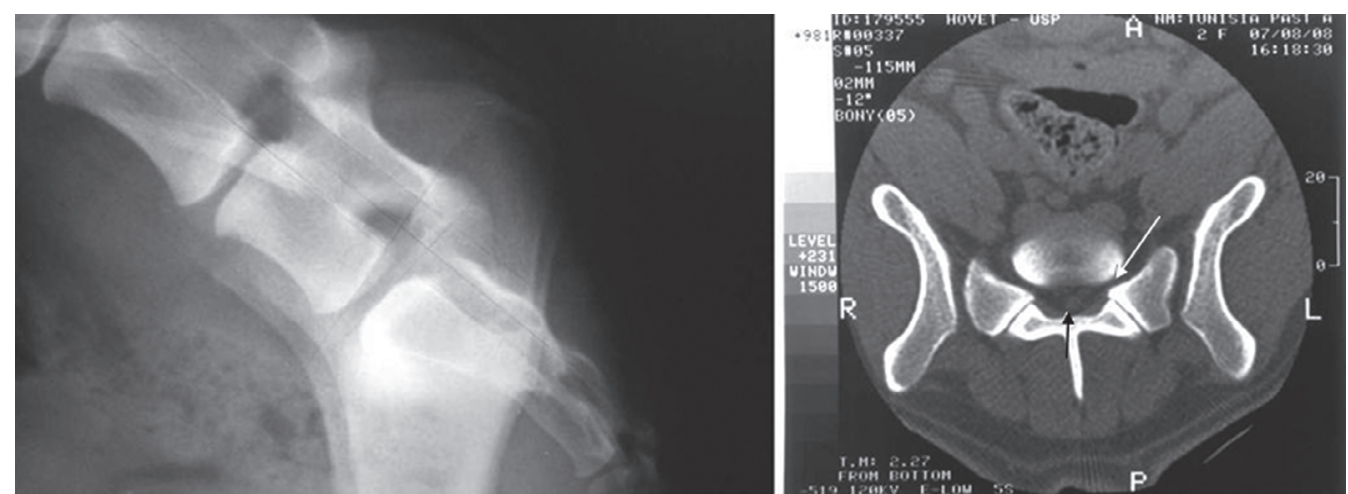

Figura 4 - Imagem radiográfica da região lombossacra na posição sob ventroflexão dos membros pélvicos e tomográfica digitalizadas com corte transversal de $02 \mathrm{~mm}$ de espessura, no espaço intervertebral entre L7-S1, de um cão do Grupo A. Notar, à TC, o aspecto normal dos foramens intervertebrais (seta branca), a presença de gordura epidural no canal vertebral, ao redor da porção terminal do saco dural (seta preta). FMVZ-USP- São Paulo - 2008 


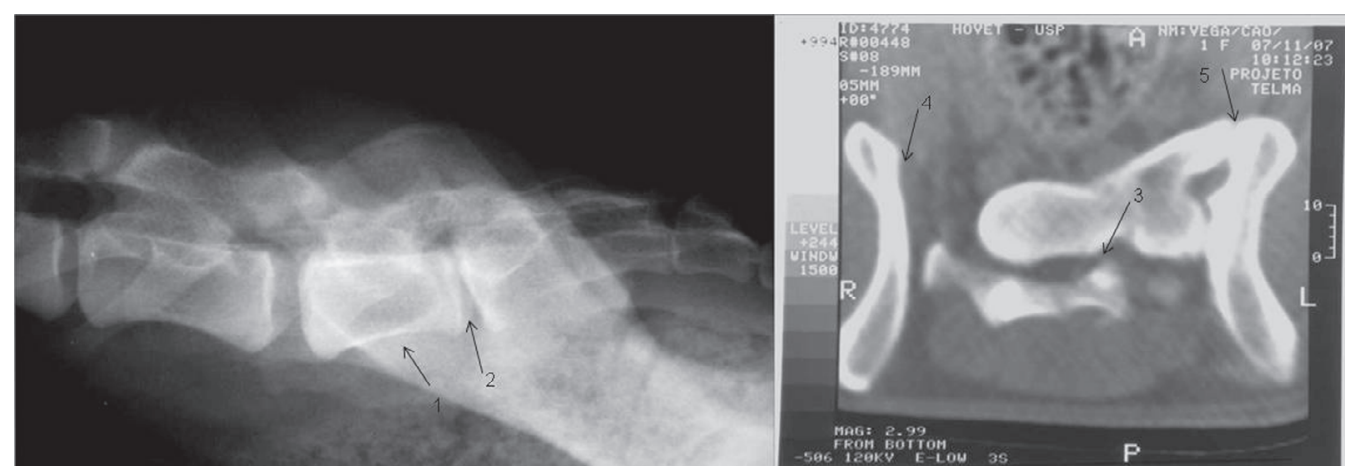

Figura 5 - Imagem radiográfica da região lombossacra na posição neutra dos membros pélvicos e tomográfica digitalizadas com corte transversal de $05 \mathrm{~mm}$ de espessura realizado junto à epífise caudal de $\mathrm{L} 7$, de um cão do grupo B. Visibilizou-se ao RX vértebra de transição lombossacra (lombarização de S1) (setas 1 e 2) e diminuição do forâmen intervertebral esquerdo (seta 3) com assimetria das articulações sacroilíacas à TC (setas 4 e 5) - FMVZ-USP - São Paulo - 2008.

intervertebral ser malformado promovendo assim uma degeneração prematura. ${ }^{17,34}$

As radiografias convencionais são um método de diagnóstico rápido, simples e que promove uma ampla avaliação do segmento lombossacro. Por outro lado, devido à baixa acurácia em diferenciar tecidos moles, pode levar a erros de interpretação, já que a asa do ílio e o sacro obscurecem o forâmen intervertebral de L7-S1. ${ }^{6,13}$ Já a TC é eficaz na avaliação do diâmetro do forâmen intervertebral, especialmente em cães com espondiloses. ${ }^{35}$ Foi observado no grupo A OFIV, somente pela TC, em 46,15\% dos animais. No grupo B, a OFIV esteve presente ao exame radiográfico, em $75 \%$, e na TC em 41,66\%. E no exame radiográfico do grupo $\mathrm{C}$ a OFIV foi visibilizada em todos os animais, e em $80 \%$ pela TC. Concordouse então, de que a visibilização radiográfica da opacificação/obliteração do forâmen intervertebral entre L7-S1 está sujeita a falsos positivos. Tendo em vista que no grupo A $61,53 \%$ dos animais apresentaram protrusão discal à TC conforme já externado por Thrall ${ }^{14}$ alguns animais com protrusão discal entre L7-S1 podem não ter alterações radiográficas.

Os achados tomográficos mais frequentes nos cães com estenose lombossacra são: retificação central do disco intervertebral, diminuição da gordura epidural, partes moles hiperatenuadas, proliferações osteofíticas, deslocamento do saco dural, alterações nos processos articulares e diminuição do canal vertebral e/ou forâmen intervertebral. ${ }^{13,31,32} \mathrm{Na}$ presente pesquisa constatou-se a retificação central do disco intervertebral nos animais dos três grupos sendo 30,76\%(A), 16,66\%(B) e $20 \%(C)$. No grupo A, a gordura epidural estava diminuída em $23,07 \%$, no B $50 \%$ e no grupo C, $60 \%$ dos animais. O deslocamento do saco dural foi visibilizado em um animal (7,69\%) do grupo A e um animal $(20 \%)$ do grupo C. No grupo A, $15,38 \%$ dos animais possuíam os processos articulares de L7-S1 maiores. No grupo B, dos doze animais, 58,33\% possuíam degeneração dos processos articulares e 8,3\% com processos articulares maiores. No grupo C, $80 \%$ possuíam degeneração dos processos articulares. Assim, frente a esses resultados, e concordando com Tarvin e Prata $^{11}$, Rossi et al. ${ }^{12}$ e Schmid e Lang ${ }^{30}$, levantou-se a hipótese de que animais assintomáticos, considerados grupo A ou $\mathrm{B}$ no presente estudo, podem dependendo da degeneração discal, hereditariedade, fatores metabólicos e atividade física ${ }^{8,12}$, vir a ser classificado como grupo C (sintomáticos) com o passar do tempo.

Algumas alterações tomográficas, tais como a estenose do canal vertebral e a diminuição da gordura epidural na junção lombossacra, presente em 23,07\% dos animais no grupo A, podem ser insignificantes clinicamente, especialmente em 
cães idosos. ${ }^{31}$

Concordando com Jones e Inzana ${ }^{31}$ notou-se que a degeneração dos processos articulares dos corpos vertebrais aparece na TC como uma diminuição de espaço entre esses processos acompanhada de osteófitos peri-articulares, esclerose do osso subcondral, cistos subcondrais e/ou hipertrofia desses processos (Figura 6).

No presente trabalho a espessura dos cortes realizados na junção lombossacra, na $\mathrm{TC}$, foi de $05 \mathrm{~mm}$ junto à epífise caudal de L7 e de $02 \mathrm{~mm}$ no espaço intervertebral entre L7-S1. Porém, segundo Jones, Banfield e $\operatorname{Ward}^{36}$, a espessura sugerida é de $01 \mathrm{~mm}$ para avaliação de abaulamento discal, já que colimações finas reduzem erros causados por volume parcial, além de aumentarem a resolução da imagem.

Dentre as vantagens da TC em relação ao RX pode-se relacionar: a melhor resolução dos tecidos moles e a possibilidade de fazer cortes seccionais de uma região. ${ }^{13}$ A TC permite, ainda, avaliar as reentrâncias laterais, forâmen intervertebral e processos articulares proporcionando uma avaliação mais detalhada do segmento lombossacro como se pôde observar neste estudo. Múltiplas modalidades de imagem são úteis no diagnóstico da SCE, porém algumas possuem uma baixa sensibilidade. Entretanto, com a disponibilidade da TC e futuramente da ressonância magnética, promove-se um incremento na qualidade da imagem aumentando a sensibilidade à alterações precoces, aperfeiçoando o diagnóstico da SCE. ${ }^{13}$

Faz-se premente a realização de estudos futuros correlacionando os achados da tomografia computadorizada e ressonância magnética, do segmento lombossacro, com os achados cirúrgicos. Assim, frente ao exposto e tendo em vista a escassez de informações pertinentes a aspectos básicos relacionados ao padrão racial estabelecido nesta pesquisa, cabe ressaltar que um estudo prospectivo de acompanhamento desses animais seria de grande valia para que os achados radiográficos e principalmente tomográficos sejam interpretados com maior propriedade.

\section{Conclusão}

Tendo em vista os resultados obtidos no presente estudo, pôde-se concluir que a exata função das radiografias sob estresse, para diagnosticar compressões na cauda equina, é ainda incerta, sendo que as imagens radiográficas do segmento lombossacro com alterações degenerativas ou sinais de instabilidade, nem sempre

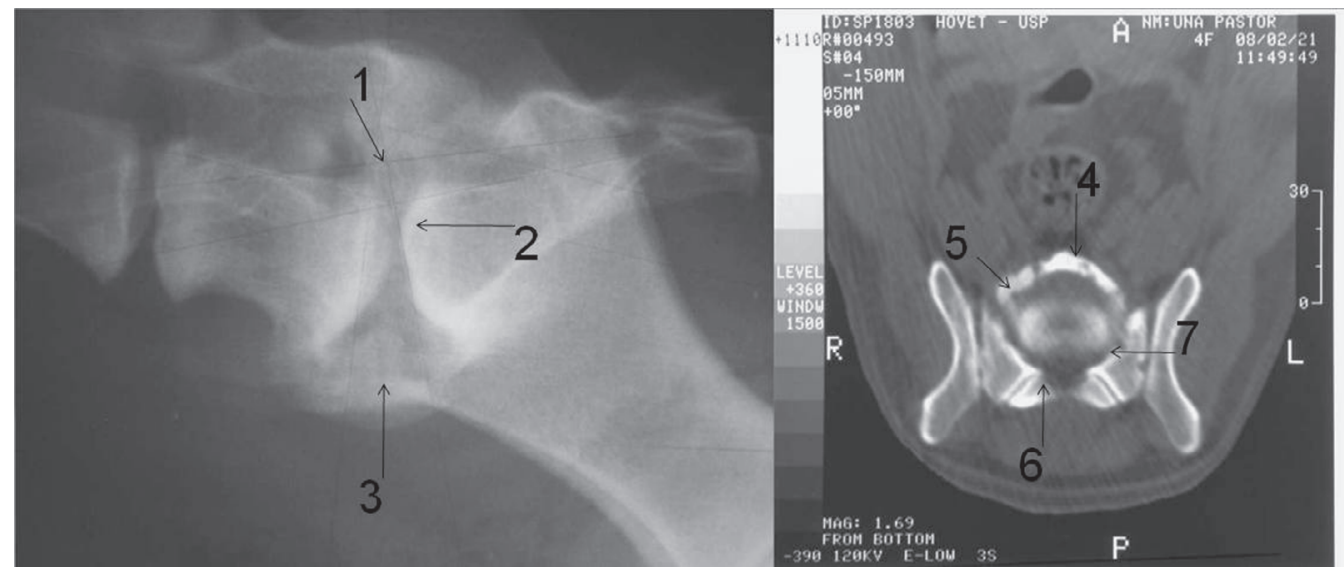

Figura 6 - Imagem radiográfica da região lombossacra na posição neutra dos membros pélvicos e tomográfica digitalizadas com corte transversal de $05 \mathrm{~mm}$ de espessura realizado junto à epífise caudal de $\mathrm{L} 7 \mathrm{de}$ um cão do grupo C. Visibilizou-se ao RX opacificação do forâmen intervertebral (seta 1), diminuição do espaço intervertebral (seta 2) e espondilose anquilosante ventral (seta 3) entre L7-S1. À TC visibilizou-se espondiloses ventrolaterais (setas 4 e 5), degeneração dos processos articulares de L7 e S1(seta 6) e obliteração bilateral do forâmen intervertebral (seta 7). FMVZ-USP - São Paulo - 2008. 
indicam compressão da cauda equina.

Nos cães com estenose lombossacra degenerativa, a compressão da cauda equina será exacerbada quando os membros pélvicos forem estendidos caudalmente (dorsoextensão) e aliviada quando os membros pélvicos são fletidos (ventroflexão).

A tomografia computadorizada foi mais detalhada que a radiografia convencional, permitindo a avaliação nas dimensões do canal vertebral, foramens intervertebrais e principalmente processos articulares.

É importante ressaltar que o estabelecimento do diagnóstico e prognóstico da afecção lombossacra deve estar sempre baseado na análise conjunta do exame neurológico, ortopédico e achados dos exames de imagem, e não exclusivamente nos achados radiográficos.

\section{Radiographics and tomographics findings of the lumbosacral junction in German Sheperd dogs: comparative study}

\section{Abstract}

The name cauda equina syndrome defines the clinical signs that come from the sensory and or motor neural dysfunction caused by the terminal part of the spinal cord and adjacent nerve roots damages. The stenosis lumbosacral is the most frequent cause, correlating to the alterations of the soft tissues and/ or the bone tissues in the lumbosacral segment. The aim of this study was to analyze critically the real contribution of diagnostic imaging (X-Ray and CT), of the lumbosacral region of 30 German shepherd dogs. There were thirteen animals that belonged to the group (A) without clinical signs and XRay alterations in the lumbosacral segment; twelve animals belonged to the group (B) without clinical signs, with X-Ray alterations in the lumbosacral segment; five animals belonged to the group (C) with clinical signs and they had X-Ray alterations in the lumbosacral segment. All exams were submitted to one evaluation report. The CT examination showed being superior in the evaluation of the vertebral canal, intervertebral foramen and the articular processes, which could be evaluated with a greater number of details. It was concluded with this research that the two modalities of images complement each other, becoming important tools in the clinicalsurgical evaluation in the lumbosacral segment, helping in the diagnosis, prognostic and therapeutic to be adopted.

\section{Referências}

1 EVANS, H. E.; CHRISTENSEN, G. C. The skeleton. In: Miller's - Anatomy of the dog. 2. ed. Philadelphia: Saunders. 1979. cap. 4, p. 107-224.

2 MORGAN, J. P.; BAILEY, C. S. Cauda equine syndrome in the dog: Radiographic evaluation. Journal of Small Animal Practice, v. 31, p. 69-77, 1990.

3 WATT, P. R. Degenerative lumbosacral stenosis in 18 dogs. Journal of Small Animal Practice, v. 32, p. 125-134, 1991.

4 MORGAN, J. P.; BAHR, A.; FRANTI, C. E.; BAILEY, C. S. Lumbosacral transitional vertebrae as a predisposing cause of cauda equine syndrome in German Shepherd Dogs: 161 cases (1987-1990). Journal of American
Key words:

Dogs.

Lumbosacral junction. Radiography. Tomography.
Veterinarian Medical Association, v. 202, p. 1877-1882, 1993.

5 BOJRAB, M. J. Técnicas atuais em cirurgia de pequenos animais. 3. ed. São Paulo: Roca. 1996. cap. 43, p. 565-597.

6 SLATTER, D. Manual de cirurgia de pequenos animais. 2. ed. São Paulo: Manole, 1998. cap. 134, p. 11361149.

7 LORENZ, M. D.; KORNEGAY, J. N. Localização das lesões no sistema nervoso. Neurologia veterinária. 4. ed. Barueri: Manole, 2006. cap. 2, p.45-74.

8 SELMI, A. L.; PEREIRA, P. M. Patologias lombossacras e síndrome da cauda eqüina no cão. Veterinária Notícias, v. 4, n. 1, p. 125-130, 1998. 
9 MORGAN, J. P.; WIND, A.; DAVIDSON, A. P. Enfermedad lumbosacra. Enfermidades articulares y ósseas hereditárias del perro. Buenos Aires: Editorial Intermédica. 2001. cap. 6, p. 209-229.

10 BASILE JÚNIOR, R.; BARROS FILHO, T. E. P. Espondilolisteses In: BARRO FILHO, T. E. P.; BASILE JÚNIOR, R. (Org.). Coluna vertebral. 1. ed. São Paulo: Sarvier, 1995. v. 1, p. 115-131.

11 TARVIN, G.; PRATA, R. G. Lumbosacral stenosis in dogs. Journal of the American Veterinary Medical Association, v. 177, p. 154-159, 1980.

12 ROSSI, F.; SEILER, G.; BUSATO, A.; WACKER, C.; LANG, J. Magnetic resonance imaging of articular process joint geometry and intervertebral disk degeneration in the caudal lumbar spine (L5-S1) of dogs with clinical signs of cauda equine compression. Veterinary Radiology e Ultrasound, v. 45, n. 5, p. 381-387, 2004.

13 RAMIREZ, O.; THRALL, D. E. A review of imaging techniques for canine cauda equine syndrome. Veterinary Radiology e Ultrasound, v. 39, n. 4, p. 283-296, 1998.

14 THRALL, D. E. The vertebrae. Textbook of veterinary diagnostic radiology. 5. ed. Philadelphia: Saunders, 2007. cap. 11, p. 179-193.

15 SISSON, A. F.; LECOUTER, R. A.; INGRAM, J. T.; PARK, R. D.; CHILD, G. Diagnosis of cauda equina abnormalities by using electromyography, discography, and epidurography in dogs. Journal of Veterinary Internal Medicine, v. 6, p. 253-263, 1992.

16 JONES, J. C.; SHIRES, P. K.; INZANA, K. D.; SPONENBERG, D. P.; MASSICOTTE, C.; RENBERG, W.; GIROUX, A. Evaluation of canine lumbosacral stenosis using intravenous contrast-enhanced computed tomography. Veterinary Radiology e Ultrasound, v. 40, n. 2 , p. $108-114,1999$

17 FLÜCKIGER, M. A.; DAMUR-DJURIC, N.; HÄSSIG, M.; MORGAN, J. P.; STEFFEN, F. A lumbosacral transitional vertebra in the dog predisposes to cauda equine syndrome. Veterinary Radiology \& Ultrasound, v. 47, n. 1, p. 39-44, 2006.

18 INDRIERI, R. J. Lumbosacral stenosis and injury of the cauda equina. Veterinary Clinics of North America: Small Animal Practice, v. 18, n. 3, p. 697-710, 1988.

19 PRATA, R. G. Moléstias da coluna vertebral lombossacra. In: SLATTER, D. Manual de cirurgia de pequenos animais. 2. ed. São Paulo: Manole, 1998. cap. 134 , p. $1136-1149$.

20 GREENE, C. E. Clinical microbiology and infectious disease of the dog and the cat. Philadelphia: Saunders, 1984, p. 967.

21 CHRISMAN, C. L. Self-mutilation. In: CHRISMAN, C. L. Problems in small animal neurology. 2. ed. Philadelphia: Lea \& Febiger, 1991. cap. 20, p. 469-477.

22 SCOTT, D. W.; MILLER, W. H.; GRIFFIN, C. E.
Muller \& Kirk. Dermatologia de pequenos animais. 5. ed. Rio de Janeiro: Interlivros, 1996. p. 1130.

23 LENEHAM, T. M.; TARVIN, G. B. Surgical treatment of cauda equina compression syndrome. In: BOJRAB, M. J. Current techniques in small animal surgery. 3. ed. Philadelphia: Lea \& Febiger, 1990. p. 629-635.

24 BARTHEZ, P. Y.; MORGAN, J. P.; LIPSITZ, D. Discography and epidurography for evaluation of the lumbosacral junction in dogs with cauda equine syndrome. Veterinary Radiology \& Ultrasound, v. 35, n. 3, p. 152-157, 1994.

25 FOSSUM, T. W. Cirurgia de pequenos animais. 1. ed. São Paulo: Roca, 2001. cap. 36. p. 1253-1260.

26 SUWANKONG, N. VOORHOUT, G.; HAZEWINKEL, H. A. W.; MEIJI, B. P. Agreement between computed tomography, magnetic resonance imaging, and surgical findings in dogs with degenerative lumbosacral stenosis. Journal of the American Veterinary Medical Association, v. 229, n. 12, p. 1924-1928, 2006.

27 MATTOON, J. S.; KOBLIK, P. D. Quantitative survey radiographic evaluation of the lumbosacral spine of normal dogs and dogs with degenerative lumbosacral stenosis. Veterinary Radiology \& Ultrasound, v. 34, n. 3, p. 194-206, 1993.

28 SCHULMAN, A. J.; LIPPINCOTT, C. L. Canine cauda equine syndrome. Compendium on Continuing Education. Small Animal Practice, v. 10, n. 7, p. 835844, 1988.

29 LECOUTER, R. A.; CHILD, G. Moléstias da medula espinal. In: ETTINGER, S. J. Tratado de medicina interna veterinária. 3. ed. Rio de Janeiro: Manole, 1992. cap. 62, p. 655-736.

30 SCHMID, V.; LANG, J. Measurements on the lumbosacral junction in normal dogs and those with cauda equine compression. Journal of Small Animal Practice, v. 34, p. 437-442, 1993.

31 JONES, J. C.; INZANA, K. D. Subclinical CTabnormalities in the lumbosacral spine of older largebreed dogs. Veterinary Radiology e Ultrasound, v. 41, n.1, p. 19-26, 2000.

32 AXLUND, T. W.; HUDSON, J. A. Computed tomography of the normal lumbosacral intervertebral disc in 22 dogs. Veterinary Radiology e Ultrasound, $v$. 44 , n. 6 , p. $630-634,2003$

33 MORGAN, J. P.; ATILOLA, M.; BAILEY, C. S. Vertebral canal and spinal cord mensuration: A comparative study of its effect on lumbosacral myelography in the Dachshund and German Shepherd Dog. Journal of the American Veterinary Medical Association, v. 15, n. 8, p. 951-957, 1987.

34 HUGHES, R. J.; SAIFUDDIN, A. Imaging of lumbosacral transitional vertebrae. Clinical Radiology, v. 59, p. 984-991, 2004.

35 HANNA, F. Y. Lumbosacral osteochondrosis: 
radiological features and surgical management in 34 dogs. Journal of Small Animal Practice, v. 42, p. 272-278, 2001.

36 JONES, J. C.; BANFIELD, C. M.; WARD, D. L. Association between postoperative outcome and results of magnetic resonance imaging and computed tomography in working dogs with degenerative lumbosacral stenosis. Journal of American Veterinary Medical Association, v. 216, n. 11, p. 1769-1774, 2000. 